\title{
New Acyl-Group Transfer Polymerization of Thiiranes Using Carboxylic Acid Derivatives and Quaternary Onium Salts
}

\author{
Atsushi Kameyama, Katsuya Shimotsuma, and Tadatomi Nishikubo* \\ Department of Applied Chemistry, Kanagawa University, Rokkakubashi, \\ Kanagawa-ku, Yokohama 221, Japan \\ (Received October 28, 1995)
}

\begin{abstract}
A new acyl-group transfer polymerization of thiiranes using carboxylic acid derivatives and quaternary onium salts was investigated. 3-Phenoxypropylene sulfide (PPS) was polymerized efficiently by $S$-phenyl thioacetate in the presence of tetrabutylammonium chloride, bromide, or tetrabutylphosphonium chloride to give the corresponding polysulfide with a $S$-acetyl group at the polymer terminal. The polymerization of 3-butoxypropylene sulfide (BPS) and cyclohexene sulfide (CHS) also proceeded under the similar conditions to afford the corresponding polymers. It was found from the polymer structures and results of post-polymerization that the polymerization proceeded transferring an acyl group in each propagating step. It was demonstrated that the acyl-group transfer polymerization has living nature. Furthermore, di- and tri-block copolymers of a variety of thiiranes were successfully synthesized by the present acyl-group transfer polymerization.

KEY WORDS Acyl Group/Group Transfer Polymerization/Thiiranes / Carboxylic Acid Derivatives Q Quaternary Onium Salts / Block Copolymer /
\end{abstract}

Group transfer polymerization is a new living polymerization for acrylic and methacrylic monomers, which was reported in the first by Webster and his co-workers. ${ }^{1}$ The concept of group transfer polymerization is that a functional group transfers at a growing chain terminal in each propagation step to give a living polymer. Many studies on the group transfer polymerization of various methacrylates ${ }^{2,3}$ including mechanistic investigations ${ }^{4,5}$ have been reported for a decade. The group transfer polymerization of silylvinyl ethers using aromatic aldehydes as initiators in the presence of Lewis acid catalysts has also been reported. ${ }^{6-8}$

These group transfer polymerizations are based on Michael addition reaction of ketenesilylacetals with $\alpha, \beta$ unsaturated esters, and aldol condensation of aldehydes with silylenol ethers, respectively. That is, certain compounds containing organic silyl groups are required to achieve these group transfer polymerizations. Furthermore, it should be noted that the transferring groups during the polymerizations are restricted to trimethylsilyl or trialkylsilyl groups.

Meanwhile, the authors have reported new polymer synthesis based on the addition reaction of cyclic ethers ${ }^{9}$ or sulfides ${ }^{10}$ with various carboxylic acid derivatives. For example, the addition reaction of oxiranes, or thiiranes with acyl chlorides using quaternary onium salts or crown ether complexes as catalysts proceeded very smoothly and regioselectively to give the corresponding carboxylic acid derivatives under mild conditions. The addition reaction of cyclic ethers were successfully applied to polyester synthesis by a polyaddition of bis(cyclic ether)s ${ }^{11,12}$ with diacyl chlorides using the catalysts.

The most interesting characteristic of the addition reaction of the heterocycles with carboxylic acid derivatives is that the reactions proceed regioselectively under neutral conditions to afford the corresponding "carboxylic acid esters".

Based on a result that the addition reaction of thiiranes

* To whom all correspondence should be addressed. with the carboxylic acid derivatives using aforementioned catalysts gives $S$-thioesters, we found a new group transfer polymerization of thiiranes ${ }^{13}$ initiated by carboxylic acid derivatives, in which an acyl group transfers in each propagating step. It is of an advantage that the polymerization is achieved by using general organic reagents for initiators and catalysts.

In this paper, the authors describe the acyl-group transfer polymerization of thiiranes using carboxylic acid derivatives as initiators and quaternary onium salts as catalysts. The polymerization behavior as group transfer polymerization was investigated in detail. Furthermore, di-block copolymers and tri-block copolymers of various thiiranes were synthesized by the present polymerization.

\section{EXPERIMENTAL}

\section{Measurements}

${ }^{1} \mathrm{H}$ NMR spectra were obtained on a JEOL EX-90 or a FX-200 operating in the pulsed Fourier-transform (FT) modes, using tetramethylsilane (TMS) as an internal standard in chloroform- $d_{6}$. IR spectra were recorded on a JASCO IR-700. The $M_{n}$ and $M_{w} / M_{n}$ of polymers were measured with a TOSOH HLC-8020 GPC unit using TSK-Gel columns (eluent, $N, N$-dimethylformamide (DMF); calibration, poly(ethylenoxide) or polystyrene standards).

\section{Materials}

3-Phenoxypropylene sulfide (PPS) was prepared from 3-phenoxypropylene oxide with thiourea according to the reported procedure. ${ }^{14}$ Yield $81 \%$. bp $86.0-87.5^{\circ} \mathrm{C} /$ $0.9 \mathrm{mmHg}$, MS $(\mathrm{m} / \mathrm{z})$; 166. 3-Butoxypropylene sulfide (BPS) was prepared from 3-butoxypropylene oxide in $46 \%$ yield. bp $78.0^{\circ} \mathrm{C} / 13 \mathrm{mmHg}$. Cyclohexene sulfide (CHS) was also prepared from cyclohexene oxide in $47 \%$ yield. bp $54-55^{\circ} \mathrm{C} / 12 \mathrm{mmHg}$. $S$-Phenyl thioacetate (PTA) (bp 77.0 $-79.0^{\circ} \mathrm{C} / 3.0 \mathrm{mmHg}$ ) and $S$-benzyl thioacetate (BTA) (bp $125.0^{\circ} \mathrm{C} / 17.0 \mathrm{mmHg}$ ) were prepared by the reaction of acetyl chloride with benzenethiol, 
or $\alpha$-toluenethiol using equimolar triethylamine, respectively, then purified by distillation under reduced pressure in $74 \%$ and $81 \%$ yields. Thietane (TE) was purified by twice distillation. Acetyl chloride (AC), benzoyl chloride (BC), dodecanoyl chloride (DC), 4-chlorobenzoyl chloride (CBC), and 4-cyanobenzoyl chloride (CNBC) were purified by conventional method. Tetrabutylammonium bromide (TBAB) was purified by recrystallization from dried ethyl acetate. Tetrabutylammonium chloride (TBAC), tetrabutylphosphonium chloride (TBPC), 18-crown-6 (18-C-6), LiCl, LiBr, and CsF were used as received.

\section{Addition Reaction of PPS with Carboxylic Acid Deriva- tives}

The reaction of PPS with BC was carried out as follows; TBAC $(0.056 \mathrm{~g}, 0.2 \mathrm{mmol})$ was placed in ample tube under dry atmosphere, and vacuum dried at $70^{\circ} \mathrm{C}$ for $5 \mathrm{~h}$. PPS (0.665 g, $4 \mathrm{mmol})$ and $\mathrm{BC}(0.562 \mathrm{~g}, 4 \mathrm{mmol})$ was added into the ample tube, then the tube was sealed to heat at $90^{\circ} \mathrm{C}$ for $24 \mathrm{~h}$. The reaction mixture was diluted with chloroform, washed two times with water, then dried with $\mathrm{MgSO}_{4}$. After filtration of $\mathrm{MgSO}_{4}$, chloroform was evaporated to isolate a product. The obtained product was purified by silica gel column chromatography (eluent, chloroform-carbontetrachloride $(1: 5, \mathrm{v} / \mathrm{v}))$ to give the product (syrup). Yield $=1.032 \mathrm{~g}(84 \%)$. IR (neat): 1666 $\left(v_{\mathrm{C}=\mathrm{o}}\right), 1598,1494\left(v_{\mathrm{C}=\mathrm{C}}\right.$ of $\left.\mathrm{Ar}\right), 1242 \mathrm{~cm}^{-1}\left(v_{\mathrm{C}-\mathrm{o}-\mathrm{C}}\right)$. ${ }^{1} \mathrm{H}$ NMR $\left(\mathrm{CDCl}_{3}\right): 3.52\left(\mathrm{~d}, J=6.0 \mathrm{~Hz}, 2 \mathrm{H}, \mathrm{CH}_{2}-\mathrm{Cl}\right)$, $3.70-4.45\left(\mathrm{~m}, 3 \mathrm{H}, \mathrm{PhO}-\mathrm{CH}_{2}-\mathrm{CH}-\mathrm{S}\right), 6.60-8.20 \mathrm{ppm}$ (m, 10H, $\operatorname{Ar} H)$.

The reaction of PPS with PTA was carried out under the same conditions to produce a solid product. Yield $=1.185 \mathrm{~g}(93 \%) . \mathrm{mp} 51.8-52.4^{\circ} \mathrm{C}$. IR (neat): 1690 $\left(v_{\mathrm{C}=\mathrm{o}}\right), 1598,1495\left(v_{\mathrm{C}=\mathrm{C}}\right.$ of Ar $), 1242 \mathrm{~cm}^{-1}\left(v_{\mathrm{C}-\mathrm{o}-\mathrm{C}}\right) \cdot{ }^{1} \mathrm{H}$ NMR $\left(\mathrm{CDCl}_{3}\right): 2.33\left(\mathrm{~s}, 3 \mathrm{H}, \mathrm{CH}_{3}-\mathrm{CO}\right), 3.20-3.54(\mathrm{~m}$, $\left.2 \mathrm{H}, \mathrm{CH}_{2}-\mathrm{S}-\mathrm{Ph}\right), 3.80-4.55\left(\mathrm{~m}, 3 \mathrm{H}, \mathrm{PhO}-\mathrm{CH}_{2}-\mathrm{CH}-\mathrm{S}\right)$, $6.60-7.59 \mathrm{ppm}(\mathrm{m}, 10 \mathrm{H}, \operatorname{Ar} H)$.

The reaction of PPS with BTA was carried out under the same conditions to give a oligomer. Yield $=0.682 \mathrm{~g}$ $(89 \%)$. Number average molecular weight $\left(M_{n}\right)=6700$ (estimated by GPC based on poly(ethylene oxide) standards). IR (neat): $1690\left(v_{\mathrm{C}=\mathrm{o}}\right), 1597,1495\left(v_{\mathrm{C}=\mathrm{C}}\right.$ of $\mathrm{Ar}), 1237 \mathrm{~cm}^{-1}\left(v_{\mathrm{C}-\mathrm{O}-\mathrm{C}}\right) .{ }^{1} \mathrm{H}$ NMR $\left(\mathrm{CDCl}_{3}\right): 2.25(\mathrm{~s}$, $\left.\mathrm{CH}_{3}-\mathrm{CO}\right), \quad 2.55-3.70 \quad\left(\mathrm{~m}, \mathrm{CH}_{2} \mathrm{CH}-\mathrm{S}\right), 3.65$ (s, $\left.\mathrm{Ph}-\mathrm{CH}_{2}-\mathrm{S}\right), 3.70-4.60\left(\mathrm{~m}, \mathrm{PhO}-\mathrm{CH}_{2}\right), 6.60-7.50 \mathrm{ppm}$ (m, $\operatorname{Ar} H)$.

\section{Polymerization}

A typical procedure is as follows; TBAB $(0.0806 \mathrm{~g}$, $0.25 \mathrm{mmol}$ ) was placed in ample tube under dry atmosphere, and dried under reduced pressure at $70^{\circ} \mathrm{C}$ for $5 \mathrm{~h}$. PPS $(2.078 \mathrm{~g}, 12.5 \mathrm{mmol})$ and PTA $(0.038 \mathrm{~g}$, $0.25 \mathrm{mmol}$ ) was added into the ample tube, then the tube was sealed followed by heating at $90^{\circ} \mathrm{C}$ for $72 \mathrm{~h}$. The polymerization mixture was poured into methanol to precipitate a polymer. The resulted polymer was reprecipitated in $\mathrm{CHCl}_{3} /$ methanol and then collected by decantation and dried under reduced pressure to give poly(PPS). Yield $=1.634 \mathrm{~g}(95 \%)$. The polymer yield was calculated by the following equation, Yield $(\%)=[\mathrm{W} /$ $(I+T)] \times 100$, in which $W$ is weight of the obtained polymer, $I$ and $T$ are weights of the initiator and the used thiirane monomer, respectively. $M_{n}=12000$, weight average molecular weight $\left(M_{w}\right) / M_{n}=1.19$ (estimated by GPC based on polystyrene standards). IR (neat): 2922 $\left(v_{\mathrm{C}-\mathrm{H}}\right), 1691\left(v_{\mathrm{C}=\mathrm{O}}\right), 1597\left(v_{\mathrm{C}=\mathrm{C}}\right.$ of $\left.\mathrm{Ar}\right), 1239 \mathrm{~cm}^{-1}$ $\left(v_{\mathrm{C}-\mathrm{O}-\mathrm{C}}\right) .{ }^{1} \mathrm{H}$ NMR $\left(\mathrm{CDCl}_{3}\right): 2.28\left(\mathrm{~s}, \mathrm{CH}_{3}-\mathrm{CO}\right), 2.91-$ $3.10\left(\mathrm{~m}, \mathrm{CH}_{2}-\mathrm{S}\right), 3.10-3.20(\mathrm{~m}, \mathrm{~S}-\mathrm{CH}), 3.95-4.23(\mathrm{~m}$, $\mathrm{PhO}-\mathrm{CH}_{2}$ ), 6.76-6.86 (m, Ar), 6.86-7.00 (m, Ar), 7.15-7.27 ppm (m, ArH).

Poly(BPS); Yield $=0.139 \mathrm{~g}(9 \%) . M_{n}=2500, M_{w} / M_{n}=$ 1.03. IR (neat): $1689\left(v_{\mathrm{C}=\mathrm{o}}\right), 1109 \mathrm{~cm}^{-1}\left(v_{\mathrm{C}-\mathrm{o}-\mathrm{C}}\right) \cdot{ }^{1} \mathrm{H}$ $\operatorname{NMR}\left(\mathrm{CDCl}_{3}\right): 0.92\left(\mathrm{t}, J=6.2 \mathrm{~Hz}, \mathrm{CH}_{3}\right), 1.12-1.78(\mathrm{~m}$, $\left.\mathrm{CH}_{2} \mathrm{CH}_{2}\right), 2.33\left(\mathrm{~s}, \mathrm{C}(\mathrm{O})-\mathrm{CH}_{3}\right), 2.77-3.09\left(\mathrm{~m}, \mathrm{CH}_{2} \mathrm{CH}-\right.$ $\mathrm{S}), 3.44\left(\mathrm{t}, \quad J=6.2 \mathrm{~Hz}, \mathrm{Pr}-\mathrm{CH}_{2}-\mathrm{O}\right), 3.54-3.70(\mathrm{~m}$, $\left.\mathrm{O}-\mathrm{CH}_{2}-\mathrm{C}-\mathrm{S}\right), 7.12-7.47 \mathrm{ppm}(\mathrm{m}, \mathrm{ArH})$.

Poly(CHS); Yield $=0.813 \mathrm{~g}(68 \%)$. IR (neat): 1687 $\mathrm{cm}^{-1}\left(v_{\mathrm{C}=\mathrm{O}}\right) .{ }^{1} \mathrm{H}$ NMR $\left(\mathrm{CDCl}_{3}\right): 1.08-2.50 \quad(\mathrm{~m}$, $\mathrm{C}-\mathrm{CH}_{2} \mathrm{CH}_{2} \mathrm{CH}_{2} \mathrm{CH}_{2}-\mathrm{C}$ ), 2.77-3.09 (m, $\left.\mathrm{CHCH}-\mathrm{S}\right)$, 7.12-7.47 ppm (m, ArH).

\section{Post-polymerization}

A typical procedure is as follows; TBAC $(0.028 \mathrm{~g}$, $0.1 \mathrm{mmol}$ ) was placed in ample tube under dry atmosphere, and vacuum dried at $70^{\circ} \mathrm{C}$ for $5 \mathrm{~h}$. Then, the solution of poly(PPS) $\left(0.43 \mathrm{~g}, M_{n}=10300, M_{w} / M_{n}=\right.$ $1.21)$ in $3 \mathrm{ml}$ of anisole and PPS $(0.832 \mathrm{~g}, 5 \mathrm{mmol})$ was added. The ample tube was sealed and heated at $90^{\circ} \mathrm{C}$ for $72 \mathrm{~h}$. The reaction mixture was diluted with small amount of chloroform to poured into methanol. The obtained polymer was purified by twice reprecipitation with chloroform-methanol to give the post-polymer. Yield $=4.139 \mathrm{~g}(98 \%)$. The yield was calculated by the following equation, Yield $(\%)=\left[\left(P_{\mathrm{o}}-P_{\mathrm{r}}\right) / M\right] \times 100$, in which $P_{\mathrm{o}}, P_{\mathrm{r}}$, and $M$ are the weights of the obtained post-polymer, the used prepolymer, and monomer, respectively. $M_{n}=29500, M_{w} / M_{n}=1.35$. IR (neat): 1691 $\left(v_{\mathrm{C}=\mathrm{o}}\right), 1597\left(v_{\mathrm{C}=\mathrm{C}}\right.$ of Ar $), 1239 \mathrm{~cm}^{-1}\left(v_{\mathrm{C}-\mathrm{o}-\mathrm{C}}\right) \cdot{ }^{1} \mathrm{H} \mathrm{NMR}$ $\left(\mathrm{CDCl}_{3}\right): 2.30$ (s, $\left.\mathrm{CH}_{3}-\mathrm{CO}\right), 2.71-3.32\left(\mathrm{~m}, \mathrm{CH}_{2} \mathrm{CH}-\mathrm{S}\right)$, $3.68-4.32\left(\mathrm{~m}, \mathrm{PhO}-\mathrm{CH}_{2}\right), 6.76-7.48 \mathrm{ppm}(\mathrm{m}, \mathrm{Ar} H)$.

\section{Block Copolymerization}

Di-block copolymerization was carried out using poly(BPS) $\left(0.30 \mathrm{~g}, M_{n}=2500, M_{w} / M_{n}=1.03\right), 5 \mathrm{mmol}$ of monomers, and TBPC $(0.029 \mathrm{~g}, 0.1 \mathrm{mmol})$ in $0.5 \mathrm{~mL}$ of anisole similarly to the post-polymerization.

Poly(BPS-PPS); Yield $=1.106 \mathrm{~g}(97 \%) . \quad M_{n}=46500$, $M_{w} / M_{n}=1.58$. IR (neat): $1690\left(v_{\mathrm{C}=\mathrm{o}}\right), 1597,1494\left(v_{\mathrm{C}=\mathrm{C}}\right.$ of Ar), $1239 \mathrm{~cm}^{-1}\left(v_{\mathrm{C}-\mathrm{O}-\mathrm{C}}\right) .{ }^{1} \mathrm{H} \mathrm{NMR}\left(\mathrm{CDCl}_{3}\right): 0.92(\mathrm{t}$, $\left.J=6.2 \mathrm{~Hz}, \mathrm{CH}_{3}\right), 1.10-1.78\left(\mathrm{~m}, \mathrm{CH}_{2} \mathrm{CH}_{2}\right.$ (BPS)), 2.34 (s, $\left.\mathrm{CH}_{3}-\mathrm{CO}\right), 2.70-3.32\left(\mathrm{~m}, \mathrm{CH}_{2} \mathrm{CH}-\mathrm{S}\right), 3.44$ (t, $\left.J=6.2 \mathrm{~Hz}, \quad \mathrm{C} H_{2}-\mathrm{O}\right), \quad 3.54-3.82 \quad\left(\mathrm{~m}, \mathrm{O}-\mathrm{CH}_{2}-\mathrm{C}-\mathrm{S}\right)$, $3.83-4.32\left(\mathrm{~m}, \mathrm{PhO}-\mathrm{CH}_{2}\right), 6.60-7.50 \mathrm{ppm}(\mathrm{m}, \mathrm{Ar} H)$.

Poly(BPS-CHS); Yield $=0.659 \mathrm{~g}(69 \%)$. IR (neat): $1685\left(v_{\mathrm{C}=\mathrm{o}}\right), 1239 \mathrm{~cm}^{-1}\left(v_{\mathrm{C}-\mathrm{o}-\mathrm{C}}\right) \cdot{ }^{1} \mathrm{H}$ NMR $\left(\mathrm{CDCl}_{3}\right)$ : $0.92\left(\mathrm{t}, \mathrm{J}=6.2 \mathrm{~Hz}, \mathrm{CH}_{3}\right), 1.10-1.92\left(\mathrm{~m}, \mathrm{CH}_{2} \mathrm{CH}_{2}\right.$ (BPS), $\mathrm{CH}_{2} \mathrm{CH}_{2}$ (CHS)), $1.92-2.57$ (m, $\mathrm{CH}_{3}-\mathrm{CO}, \mathrm{CH}_{2}-\mathrm{C}-\mathrm{C}-$ $\mathrm{CH}_{2}$ ), 2.57-3.22 (m, $\mathrm{CH}_{2} \mathrm{CH}-\mathrm{S}$ (BPS), $\mathrm{CHCH}-\mathrm{S}$ $(\mathrm{CHS})), 3.44\left(\mathrm{t}, J=6.2 \mathrm{~Hz}, \mathrm{CH}_{2}-\mathrm{O}\right), 3.55-3.82(\mathrm{~m}$, $\left.\mathrm{O}-\mathrm{CH}_{2}-\mathrm{C}-\mathrm{S}\right)$ 7.15-7.41 ppm (m, $\left.\mathrm{ArH}\right)$.

Poly(BPS-TE); Yield $=0.306 \mathrm{~g} \quad(16 \%) . \quad M_{n}=2800$, $M_{w} / M_{n}=1.13$. IR (neat): $1689 \quad\left(v_{\mathrm{C}=\mathrm{o}}\right), 1109 \mathrm{~cm}^{-1}$ $\left(v_{\mathrm{C}-\mathrm{O}-\mathrm{C}}\right){ }^{1} \mathrm{H} \mathrm{NMR}\left(\mathrm{CDCl}_{3}\right): 0.92\left(\mathrm{t}, J=6.2 \mathrm{~Hz}, \mathrm{CH}_{3}\right)$, $1.12-1.78\left(\mathrm{~m}, \mathrm{CH}_{2} \mathrm{CH}_{2}\right.$ (BPS)), $1.86(\mathrm{t}, J=6.2 \mathrm{~Hz}$, $\left.\mathrm{C}-\mathrm{C} H_{2}-\mathrm{C}\right), 2.34\left(\mathrm{~s}, \mathrm{CH}_{3}-\mathrm{CO}\right), 2.63(\mathrm{t}, J=7.0 \mathrm{~Hz}$, 
$\left.\mathrm{CH}_{2}-\mathrm{S}-\mathrm{CH}_{2}\right), 2.77-3.09 \quad\left(\mathrm{~m}, \mathrm{CH}_{2} \mathrm{CH}-\mathrm{S}\right), 3.44$ (t, $\left.\mathrm{J}=6.2 \mathrm{~Hz}, \quad \mathrm{CH}_{2}-\mathrm{O}\right), \quad 3.54-3.80 \quad\left(\mathrm{~m}, \mathrm{O}-\mathrm{CH}_{2}-\mathrm{C}-\mathrm{S}\right)$, $7.12-7.47 \mathrm{ppm}(\mathrm{m}, \mathrm{Ar} H)$.

Tri-block copolymerization was carried out using di-block copolymers $\left(0.30 \mathrm{~g}, M_{n}=2500, M_{w} / M_{n}=1.03\right)$, $5 \mathrm{mmol}$ of monomer, and TBPC $(0.015 \mathrm{~g}, 0.05 \mathrm{mmol})$ in $0.5 \mathrm{~mL}$ of anisole similarly to the post-polymerization.

Poly(BPS-CHS-PPS); Yield $=0.928 \mathrm{~g} \quad(94 \%) . \quad M_{n}=$ 22100, $M_{w} / M_{n}=1.44$. IR (neat): $1597,1494\left(v_{\mathrm{C}=\mathrm{C}}\right.$ of $\mathrm{Ar}), 1239 \mathrm{~cm}^{-1}\left(v_{\mathrm{C}-\mathrm{O}-\mathrm{C}}\right) .{ }^{1} \mathrm{H} \mathrm{NMR}\left(\mathrm{CDCl}_{3}\right): 0.75-1.10$ $\left(\mathrm{m}, \mathrm{CH}_{3}\right), 1.10-1.85$ (m, $\mathrm{CH}_{2} \mathrm{CH}_{2}$ (BPS), $\mathrm{CH}_{2} \mathrm{CH}_{2}$ (CHS)), 1.85-2.45 (m, $\left.\mathrm{CH}_{2}-\mathrm{C}-\mathrm{C}-\mathrm{CH}_{2}\right), 2.45-3.30$ (m, $\mathrm{CH}_{2} \mathrm{CH}-\mathrm{S}$ (BPS, PPS), $\mathrm{CHCH}-\mathrm{S}$ (CHS)), 3.30-3.82 (m, $\left.\mathrm{CH}_{2}-\mathrm{O}, \mathrm{O}-\mathrm{CH}_{2}-\mathrm{C}-\mathrm{S}\right), \quad 3.82-4.40$ (m, $\left.\mathrm{PhO}-\mathrm{CH}_{2}\right)$, $6.40-7.40 \mathrm{ppm}(\mathrm{m}, \mathrm{Ar} H)$.

Poly(BPS-TE-PPS); Yield $=0.889 \mathrm{~g}(89 \%) . M_{n}=33400$, $M_{w} / M_{n}=1.44$. IR (neat): 1597, $1494\left(v_{\mathrm{C}=\mathrm{c}}\right.$ of $\left.\mathrm{Ar}\right)$, $1239 \mathrm{~cm}^{-1}\left(v_{\mathrm{C}-\mathrm{O}-\mathrm{C}}\right) .{ }^{1} \mathrm{H} \mathrm{NMR}\left(\mathrm{CDCl}_{3}\right): 0.65-1.09(\mathrm{~m}$, $\mathrm{CH}_{3}$, (BPS)), $1.09-2.10$ (m, $\mathrm{CH}_{2} \mathrm{CH}_{2}$ (BPS), $\mathrm{C}-\mathrm{CH}_{2}-\mathrm{C}$ (TE)), $2.40-3.73\left(\mathrm{~m}, \mathrm{CH}_{2}-\mathrm{S}-\mathrm{CH}_{2}\right.$ (TE), $\mathrm{CH}_{2} \mathrm{CH}-\mathrm{S}$ (BPS, PPS)), 3.29-3.82 (m, $\left.\mathrm{CH}_{2}-\mathrm{O}, \mathrm{O}-\mathrm{CH}_{2}-\mathrm{C}-\mathrm{S}\right)$, $3.82-4.34\left(\mathrm{~m}, \mathrm{PhO}-\mathrm{CH}_{2}\right), 6.40-7.42 \mathrm{ppm}(\mathrm{m}, \mathrm{Ar} H)$.

\section{RESULTS AND DISCUSSION}

\section{Addition Reaction of PPS with Carboxylic Acid De- rivatives}

The polymerization of thiiranes with carboxylic acid derivatives as initiators is anticipated to proceed in to processes, as shown Scheme 1. In initiation reaction, thiirane monomers (1) selectively react with the initiator (2) in the presence of catalysts to give the corresponding

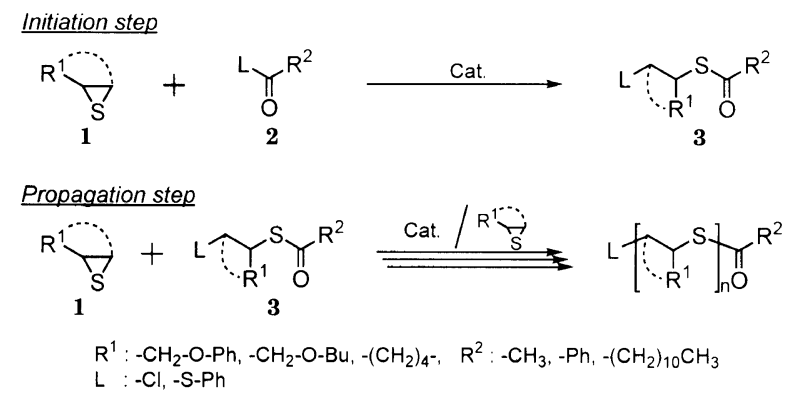

Scheme 1. adduct (3). In propagation process, $S$-thioester 3 react with $\mathbf{1}$, followed by similar reactions of the propagating $S$-thioester group with $\mathbf{1}$. Thus, the addition reaction of PPS with equimolar carboxylic acid derivatives was examined as a model reaction of the initiation reaction in the polymerization of PPS using the carboxylic derivatives. When the reaction of PPS with BC or PTA using $5 \mathrm{~mol} \%$ of TBAC as the catalyst was conducted in bulk at $90^{\circ} \mathrm{C}$ for $24 \mathrm{~h}$, the corresponding $1: 1$ adducts were obtained in high yields, respectively (Table I). On the other hand, the reaction with BTA, which reactivity is lower than that of $\mathrm{BC}$ or PTA, provided a oligomer. The IR spectrum of the obtained oligomer showed a characteristic peak (weak) due to $\mathrm{C}=\mathrm{O}$ stretching of the terminal $S$-acetyl group at a $1690 \mathrm{~cm}^{-1}$. This could be understood as follows; at first addition reaction of PPS with BTA proceeded to give a corresponding addition product $S$-alkyl thioester, then the reaction of the resulted $S$-alkyl thioester with BTA took place competitively to give the oligomer with terminal $S$-acetyl group. These mean that the reaction of PPS with active carboxylic acid derivatives such as BC or PTA using TBAC proceeded smoothly and selectively to give the corresponding addition products.

Polymerization of PPS with Carboxylic Acid Derivatives

The polymerization of PPS using carboxylic acid derivatives ( $2 \mathrm{~mol} \%$ vs. PPS) as initiators was carried out in the presence of TBAB or TBAC $(2 \mathrm{~mol} \% v s$. PPS $)$ in bulk at $90^{\circ} \mathrm{C}$. The results are summarized in Table II. The polymerization of PPS with acyl chlorides such as

Table I. Addition reaction of PPS with carboxylic acid derivatives ${ }^{a}$

\begin{tabular}{ccc}
\hline \multirow{2}{*}{$\begin{array}{c}\text { Carboxylic acid } \\
\text { derivative }\end{array}$} & Ydduct & Oield $/ \%$ \\
\cline { 2 - 3 } & 84 & Oligomer \\
\hline BC & 93 & 0 \\
PTA & 0 & $89^{\mathrm{b}}$ \\
BTA & & \multicolumn{2}{c}{}
\end{tabular}

${ }^{a}$ The reaction was carried out with PPS $(4 \mathrm{mmol})$ and carboxylic acid derivatives $(4 \mathrm{mmol})$ using TBAC $(0.2 \mathrm{mmol})$ in bulk at $90^{\circ} \mathrm{C}$ for $24 \mathrm{~h} .{ }^{\mathrm{b}}$ The yield was determined by the calculated yield of a oligomer of PPS. $M_{n}$ was 6700 , which was estimated by GPC based on poly(ethylen oxide) standards.

Table II. Polymerization of PPS with various carboxylic acid derivatives ${ }^{\mathbf{a}}$

\begin{tabular}{|c|c|c|c|c|c|c|c|}
\hline \multicolumn{3}{|c|}{ Carboxylic acid derivative } & \multirow{2}{*}{ Catalyst } & \multirow{2}{*}{$\frac{\text { Time }}{\mathrm{h}}$} & \multirow{2}{*}{$\begin{array}{c}\text { Yield }^{\mathbf{b}} \\
\%\end{array}$} & \multirow{2}{*}{$M_{n}^{\mathrm{c}}$} & \multirow{2}{*}{$M_{w} / M_{n}^{\mathrm{c}}$} \\
\hline Name & $\mathrm{R}^{2}$ & $\mathrm{~L}$ & & & & & \\
\hline (DC) & $\mathrm{C}_{11} \mathrm{H}_{23}$ & $\mathrm{Cl}$ & TBAC & 72 & 95 & 12300 & 1.25 \\
\hline (BC) & $\mathrm{Ph}$ & $\mathrm{Cl}$ & TBAC & 72 & 95 & 12400 & 1.26 \\
\hline (CBC) & 4-Cl-Ph & $\mathrm{Cl}$ & TBAC & 72 & 95 & 11600 & 1.32 \\
\hline (CNBC) & 4-CN-Ph & $\mathrm{Cl}$ & TBAC & 72 & 96 & 12100 & 1.34 \\
\hline (PTA) & $\mathrm{CH}_{3}$ & $\mathrm{SPh}$ & TBAB & 24 & 95 & 11800 & 1.22 \\
\hline$(\text { PPTA })^{d}$ & $\mathrm{CH}_{3}$ & $\mathrm{SCHR}^{\prime} \mathrm{R}^{\prime \prime}$ & TBAB & 24 & 86 & 6700 & 1.36 \\
\hline
\end{tabular}

${ }^{\text {a }}$ The reaction was carried out with PPS $(15 \mathrm{mmol})$ and carboxylic acid derivatives $(0.3 \mathrm{mmol})$ using catalyst $(0.3 \mathrm{mmol})$ in $[\mathrm{Ph}$ bulk at $90^{\circ} \mathrm{C}$. ${ }^{\mathrm{b}}$ Insoluble parts in methanol. ${ }^{\mathrm{c}}$ Estimated by GPC based on polystyrene standards. ${ }^{\mathrm{d}} S-(1-$ phenylmethyl-2phenylthio)ethyl thioacetate. 


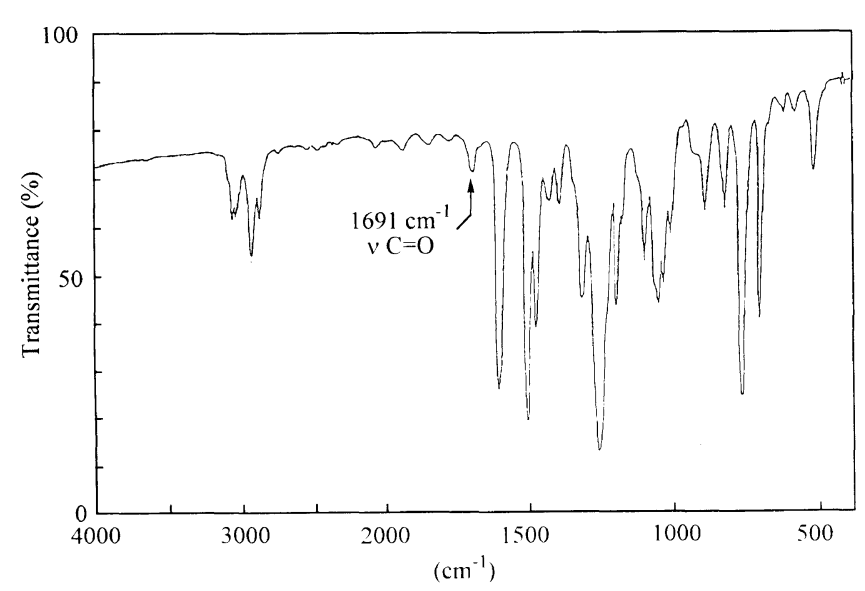

Figure 1. IR spectrum of poly(PPS). Poly(PPS), $M_{n}=12800$.

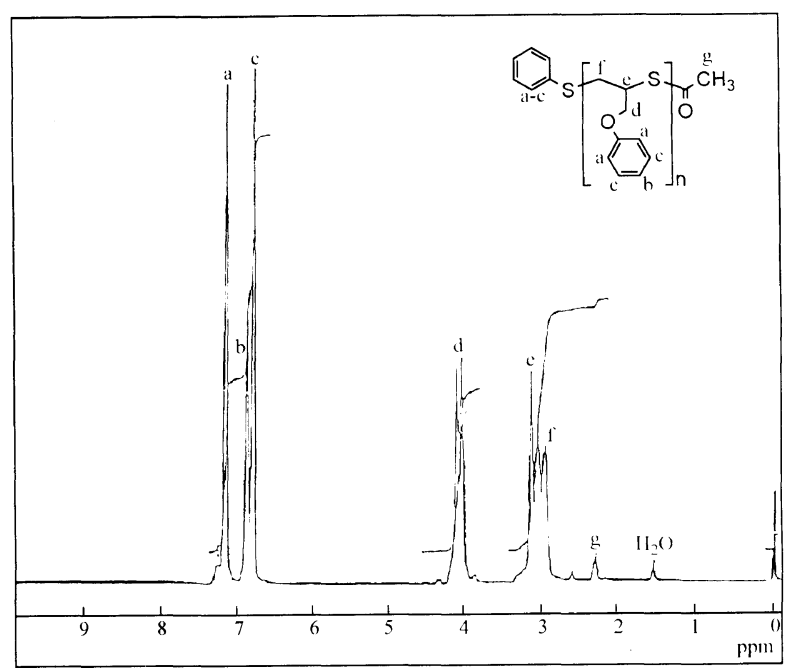

Figure 2. ${ }^{1} \mathrm{H}$ NMR spectrum of the same poly(PPS) as in Figure 1.

AC and dodecanoyl chlorides using TBAC proceeded for $72 \mathrm{~h}$ to give polymers with $M_{n}$ of about 12000 in quantitative yields. The polymerization with aromatic acyl chlorides, $\mathrm{BC}, \mathrm{CBC}$, and $\mathrm{CNBC}$ under the same conditions also provide the corresponding polymers with $M_{n}$ of about 12000 . When the polymerization was conducted using $S$-phenyl thioacetate (PTA) and TBAB, the reaction proceeded smoothly for $24 \mathrm{~h}$ to afford the corresponding polymer with $M_{n}$ of 11800 . These mean that the used carboxylic acid derivatives act as initiators for the polymerization of PPS. Furthermore, when the reaction was carried out with $S$-(1-phenoxymethyl-2phenylthio)ethyl thioacetate (PPTA) which is the addition product of PPS and PTA, the polymer with the same structure as that produced in the polymerization of PPS with PTA was obtained. This suggested that the polymerization of PPS with PTA initiated by the selective addition reaction of PTA with PPS, followed by a chain propagation from PPTA.

The structure of the obtained polymer from the polymerization with PTA and TBAB was identified by IR and ${ }^{1} \mathrm{H}$ NMR spectra. As shown in Figure 1, the IR spectrum showed a characteristic weak peak due to $\mathrm{C}=\mathrm{O}$ stretching of $S$-thioester group at $1691 \mathrm{~cm}^{-1}$. The ${ }^{1} \mathrm{H}$ NMR data indicated that the $\beta$-cleavage of the thiirane ring of PPS occurred selectively to give the polysulfide (Figure 2). Furthermore, a small signal due to $\mathrm{CH}_{3}$
Table III. Catalyst effect on the polymerization of PPS with PTA ${ }^{a}$

\begin{tabular}{|c|c|c|c|}
\hline Catalyst $^{\mathrm{b}}$ & $\frac{\text { Yield }^{\mathrm{c}}}{\%}$ & $M_{n}{ }^{\mathrm{d}}$ & $M_{w} / M_{n}{ }^{\mathrm{d}}$ \\
\hline None & 0 & 一 & - \\
\hline $\mathrm{LiCl}$ & 2 & 1500 & 1.02 \\
\hline $\mathrm{LiBr}$ & 3 & 1400 & 1.01 \\
\hline $18-\mathrm{C}-6 / \mathrm{CsF}$ & 100 & 81400 & 2.23 \\
\hline TBAC & 99 & 20600 & 1.30 \\
\hline TBAB & 95 & 11300 & 1.22 \\
\hline TBPC & 99 & 23600 & 1.36 \\
\hline
\end{tabular}

${ }^{a}$ The reaction was carried out with PPS $(25 \mathrm{mmol})$ and PTA $(0.5$ $\mathrm{mmol})$ using catalyst $(0.5 \mathrm{mmol})$ in bulk at $90^{\circ} \mathrm{C}$ for $24 \mathrm{~h} .{ }^{\mathrm{b}} 18-\mathrm{C}-6,18-$ crown-6-ether; TBAC, tetrabutylammonium chloride; TBAB, tetrabutylammonium bromide; TBPC, tetrabutylphosphonium chloride. ${ }^{\mathrm{c}}$ Insoluble parts in methanol. ${ }^{\mathrm{d}}$ Estimated by GPC based on polystyrene standards.

protons of acetyl group was observed at $2.3 \mathrm{ppm}$. These spectra data showed that the obtained polymer has terminal $S$-acetyl group, which came from PTA as the initiator. That is, PPS monomer was polymerized by PTA in the presence of TBAB involving an acetyl group transfer during each propagating process.

Although the polymerization of PPS with PTA was attempted in the absence of catalysts in bulk at $90^{\circ} \mathrm{C}$ for $24 \mathrm{~h}$, polymerization did not occur at all. The effect of the catalysts on the polymerization was investigated, and the results are summarized in Table III. Polymers with low molecular weights were obtained by the polymerization using $\mathrm{LiCl}$ or $\mathrm{LiBr}$ as catalysts. The polymerization using $18-\mathrm{C}-6 / \mathrm{CsF}$ produced a polymer with high molecular weight. However, the GPC profile of the obtained polymer suggested that a ring-opening polymerization initiated by the used catalysts also occurred as a side reaction. On the other hand, acyl group transfer polymerization proceeded selectively using TBAC, TBAB, and TBPC to give a polymer with high molecular weight and relatively narrow molecular distribution. Thus, it was proved that the quaternary onium salts catalyzed selectively the group transfer polymerization of PPS to give the expected polymer. It was also suggested that the quaternary onium salts contained chloride as the counter anion have higher catalytic activity than that with bromide.

Figure 3 shows the time-course of the polymerization of PPS using PTA and TBPC in bulk at $60^{\circ} \mathrm{C}$. The yield of polymer, which was insoluble parts in methanol, increased gradually up to $98 \%$ at $24 \mathrm{~h}$. The $M_{n}$ of the polymer also increased with reaction time, and reached to about 14000 at $24 \mathrm{~h}$. After that, no increase of the molecular weight was observed. These mean that PPS monomer was converted quantitatively to the polymer for $24 \mathrm{~h}$ during the polymerization, which proceeded in chain polymerization mode.

The relationship between the polymer yield and $M_{n}$ on the polymerization of PPS is shown in Figure 4. Although slight deviations from a straight line were observed, $M_{n}$ increased in direct proportion to the polymer yield. This result suggested the polymerization of PPS with PTA as the initiator and TBPC as the catalyst is of living nature. 


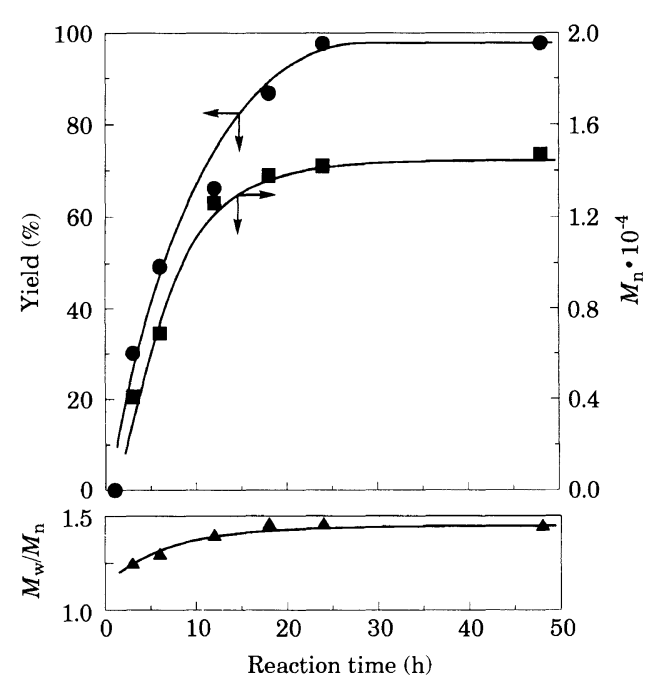

Figure 3. Time-course of the polymerization of PPS with PTA and TBPC. PPS, $12.5 \mathrm{mmol}$; PTA, $0.25 \mathrm{mmol}$; TBPC, $0.25 \mathrm{mmol}, 60^{\circ} \mathrm{C}$. $(\bullet)$, yield; ( $\mathbf{\square}), M_{n}$

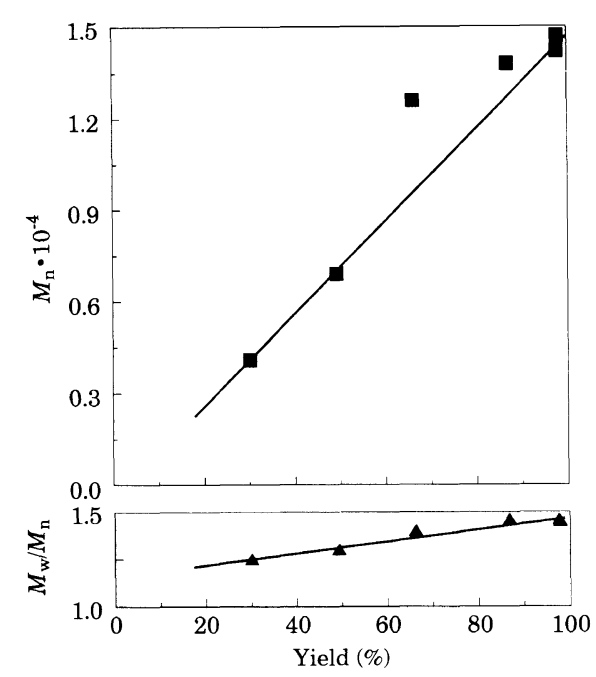

Figure 4. Relationship between yield and $M_{n}$ for the poly(PPS) as in Figure 3.

The polymerization of PPS with PTA in the presence of TBAB in bulk was carried out in various feed ratio of PPS for PTA in the range from 25 to 100 . As shown in Figure 5, the polymer was obtained in quantitative yield in each feed ratio. The molecular weight increased with the increasing the feed ratio. This means that the molecular weight of the polymer can be controlled by the feed ratios of PPS/PTA.

Various thiiranes could be polymerized using PTA and TBAB. The results are summarized in Table IV. When the polymerization of BPS was conducted at $90^{\circ} \mathrm{C}$ for 14 days, the corresponding polymer with low molecular weight was afforded in low yield. The polymerization of 1,2-substituted thiirane CHS proceeded under the same conditions to give the corresponding polymer in $68 \%$ yield. The molecular weight of the obtained polymer could not be estimated by GPC because of its insolubility in DMF. These results suggest that the reactivity of the thiiranes used increase in the following order, BPS $<$ CHS $<$ PPS. In the IR spectra of the obtained polymers, weak peak due to $\mathrm{C}=\mathrm{O}$ stretching of the terminal $S$-acetyl group was observed at about $1690 \mathrm{~cm}^{-1}$.

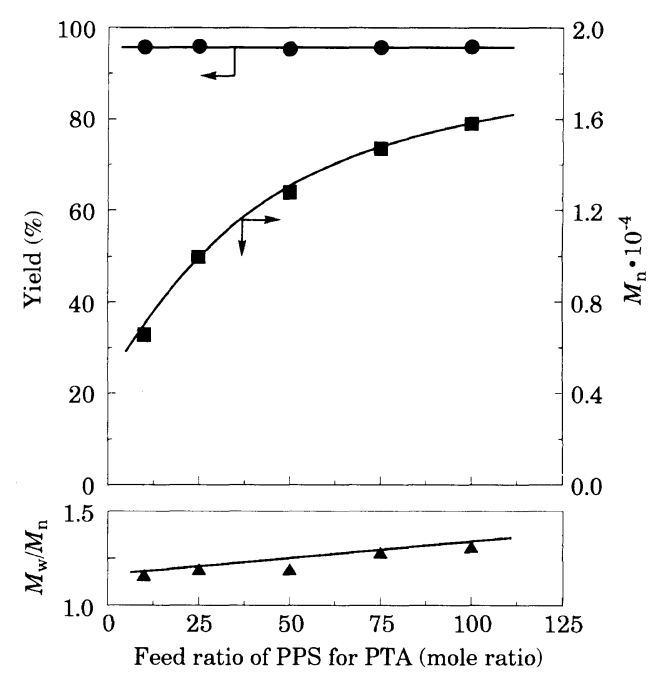

Figure 5. Effect of the feed ratio of PPS for PTA on the polymerization of PPS using TBAB. PPS, $1.25 \mathrm{mmol}, 90^{\circ} \mathrm{C}, 72 \mathrm{~h}$. (O), yield; $(\boldsymbol{\square}), M_{n}$.

Table IV. Polymerization of various thiiranes with PTA $^{\mathrm{a}}$

\begin{tabular}{|c|c|c|c|c|}
\hline \multirow{2}{*}{ Thiiranes ${ }^{b}$} & Time & Yield $^{c}$ & \multirow{2}{*}{$M_{n}^{\mathrm{d}}$} & \multirow{2}{*}{$M_{w} / M_{n}{ }^{\mathrm{d}}$} \\
\hline & day & $\%$ & & \\
\hline PPS & 1 & 95 & 10300 & 1.21 \\
\hline BPS & 14 & 9 & 1500 & 1.03 \\
\hline $\mathrm{CHS}$ & 14 & 68 & - & - \\
\hline
\end{tabular}

a The reaction was carried out with various thiiranes $(10 \mathrm{mmol})$ and PTA $(0.4 \mathrm{mmol})$ using catalyst $(0.4 \mathrm{mmol})$ in bulk at $90^{\circ} \mathrm{C}$. ${ }^{\text {b }} \mathrm{PPS}$, 3-phenoxypropylene sulfide; BPS, 3-butoxypropylene sulflde; CHS, cyclohexene sulfide. ${ }^{\mathrm{c}}$ Insoluble parts in methanol. ${ }^{\mathrm{d}}$ Estimated by GPC based on polystyrene standards.

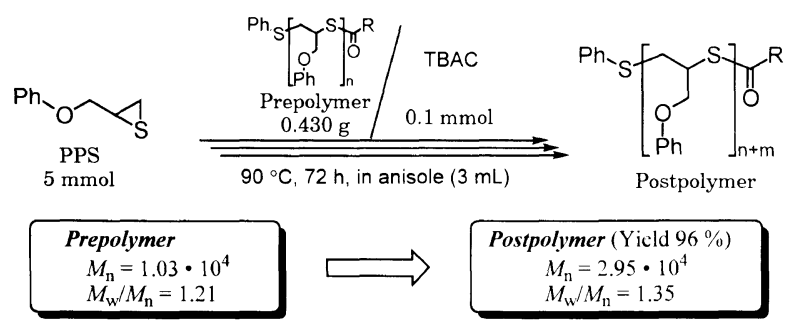

Scheme 2 .

Therefore, it was demonstrated that these thiirane monomers polymerized easily by the present reaction system to give the corresponding polymers with terminal $S$-thioester groups.

\section{Post-Polymerization and Block Copolymerizations}

Since the polymers obtained by the present polymerization have relatively stable $S$-acyl groups at the terminal, a post-polymerization can be performed using the isolated prepolymers. The post-polymerization of PPS was carried out with an isolated poly(PPS) as follows. To the solution of the polymer $\left(0.43 \mathrm{~g}, M_{n}=10300\right)$ in $3 \mathrm{ml}$ of anisole, PPS $(0.832 \mathrm{~g}, 5 \mathrm{mmol})$ and TBAC $(0.028 \mathrm{~g}, 0.1 \mathrm{mmol})$ were added, then heated at $90^{\circ} \mathrm{C}$ for $72 \mathrm{~h}$. A post-polymer with $M_{n}$ of 29500 was obtained in $98 \%$ yield (Scheme 2). The IR and ${ }^{1} \mathrm{H}$ NMR spectra of the obtained polymer proved that the polymer has the $S$-acetyl group at the terminal. As shown in Figure 6, 


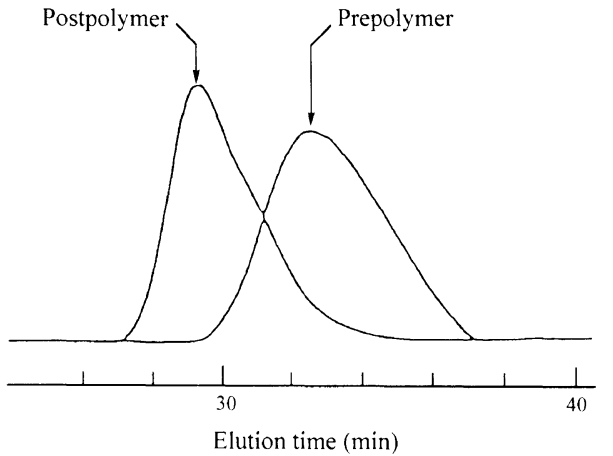

Figure 6. GPC profiles of the prepolymer and post-polymer of PPS

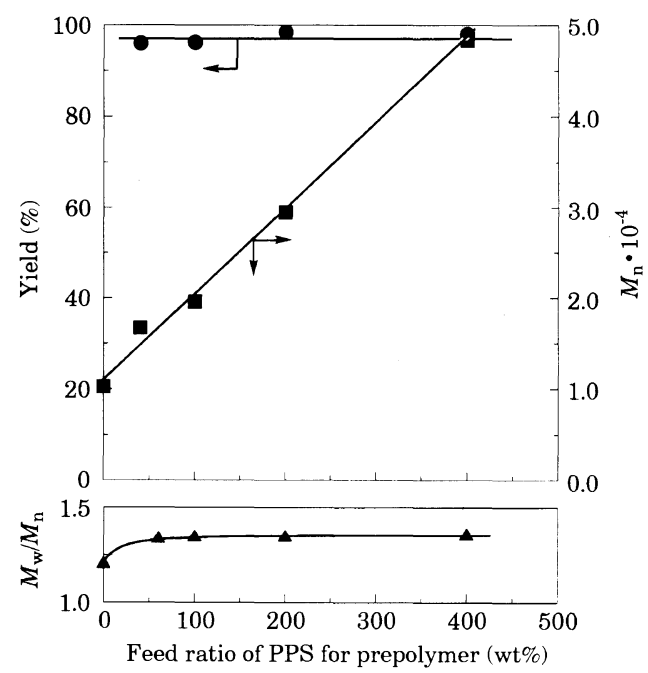

Figure 7. Effect of the feed ratio of PPS for the prepolymer on the post-polymerization of PPS. Prepolymer, $0.430 \mathrm{~g}$; TBAC, $0.1 \mathrm{mmol}$; anisole, $3 \mathrm{ml}, 90^{\circ} \mathrm{C}, 72 \mathrm{~h}$. (○), yield; $(\square), M_{n}$.

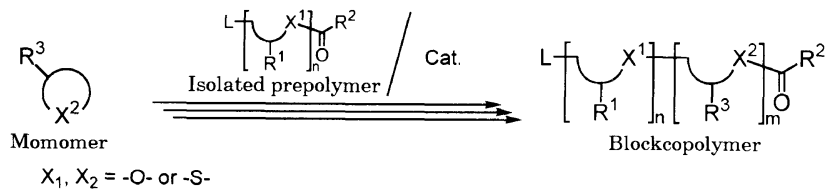

Scheme 3.

the unimodal GPC profile shifted to the higher molecular region compared with that of the prepolymer. Thus, it was found that the post-polymerization was initiated from the $S$-thioester group of the prepolymer. Figure 7 shows the relationship between feed ratio of PPS for the prepolymer to the yield and the molecular weight. The post-polymers were obtained with quantitative yields in the range of feed ratio from 60 to $400 \mathrm{wt} \%$. The molecular weight of the post-polymer increased linearly with the feed ratios. This means that the acyl group transfer polymerization has living nature.

The synthesis of certain AB-type of di-block copolymers was carried out using a poly(BPS) prepolymer $\left(M_{n}=2500, M_{w} / M_{n}=1.03\right)$, which was synthesized with PTA, in a similar manner to the previous post-polymerization (Scheme 3). The reaction of PPS with poly(BPS) using TBPC proceeded smoothly at $90^{\circ} \mathrm{C}$ for 3 days to give the corresponding di-block copolymer poly(BPS-PPS) in quantitative yield. The composition of the resulting poly(BPS-PPS) block copolymer was $30: 70$, which was determined by the intensity ratios in its ${ }^{1} \mathrm{H}$

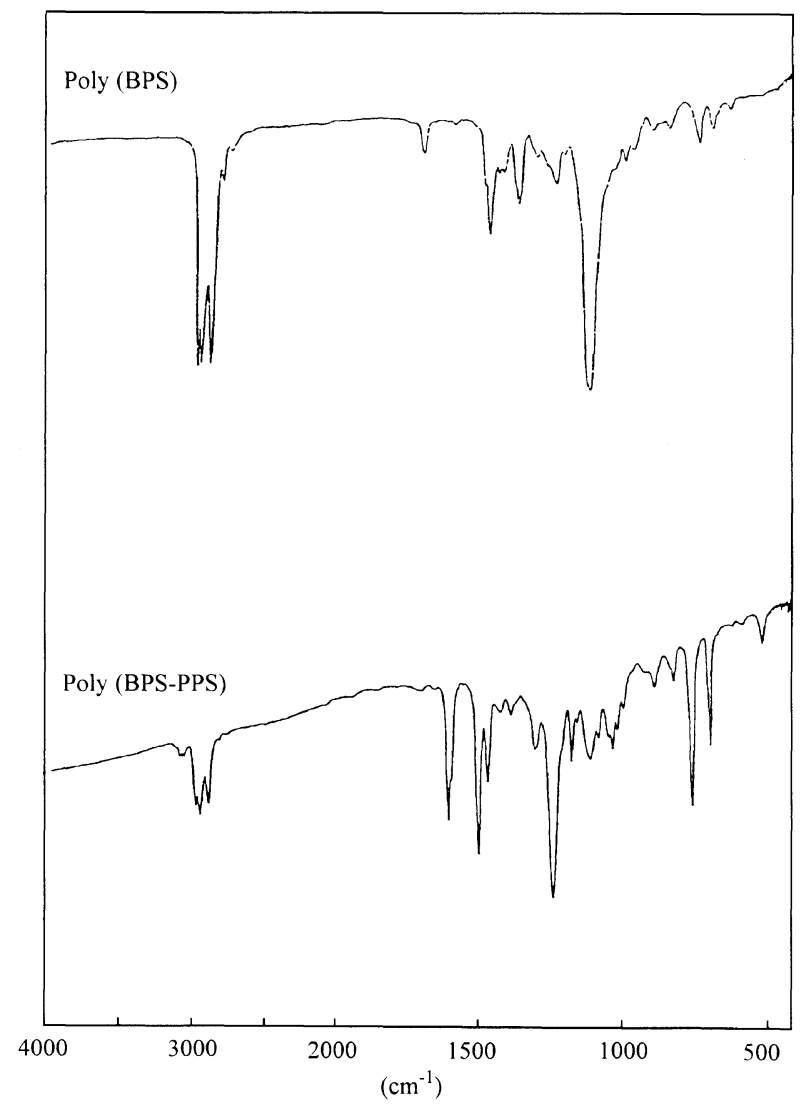

Figure 8. IR spectra of poly(BPS) and poly(BPS-PPS). Poly(BPS), $M_{n}=2500 ;$ poly(BPS-PPS), $M_{n}=46500$.

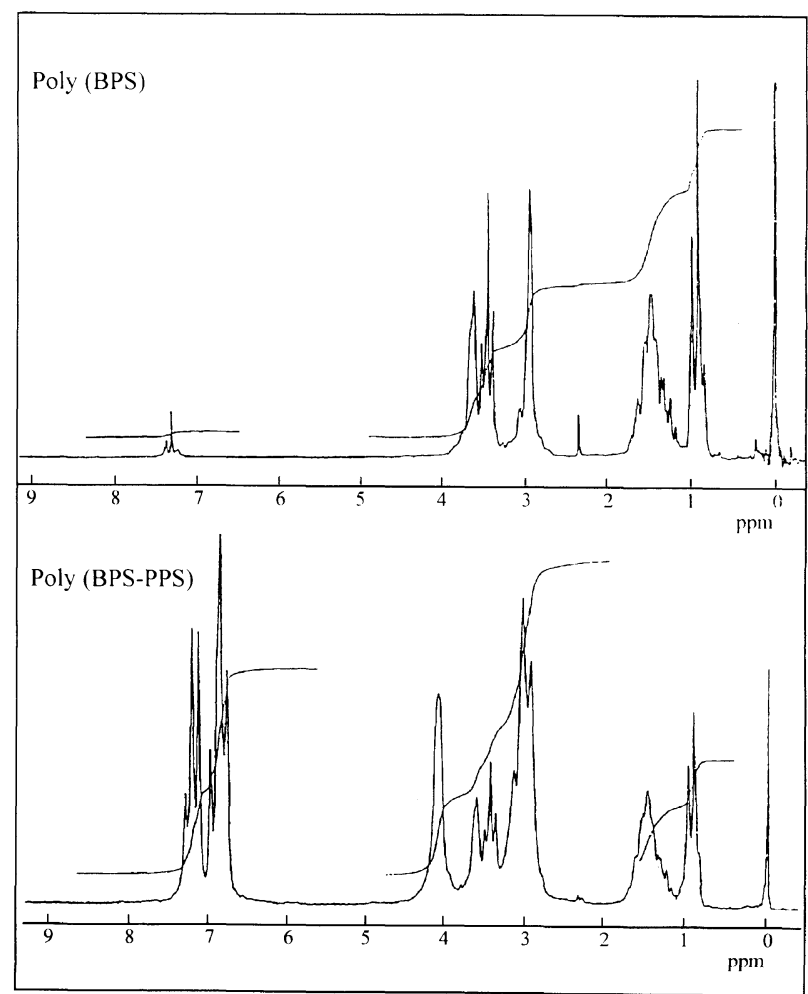

Figure 9. ${ }^{1} \mathrm{H}$ NMR spectra of poly(BPS) and poly(BPS-PPS) as in Figure 8.

NMR spectrum. The $M_{n}$ of the block copolymer was 46500 , which was relatively higher than that of the BPS-prepolymer $\left(M_{n}=2500\right)$. The reaction of CHS with the present prepolymer at $120^{\circ} \mathrm{C}$ for 3 days produced the 
corresponding poly(BPS-CHS) with $37: 63$ composition in $69 \%$ yield. When the reaction of TE, that was a four-membered cyclic sulfide, with the prepolymer was also carried out at $120^{\circ} \mathrm{C}$ for 7 days, poly(BPS-TE) with $M_{n}$ of 2800 was obtained in $16 \%$ yield.

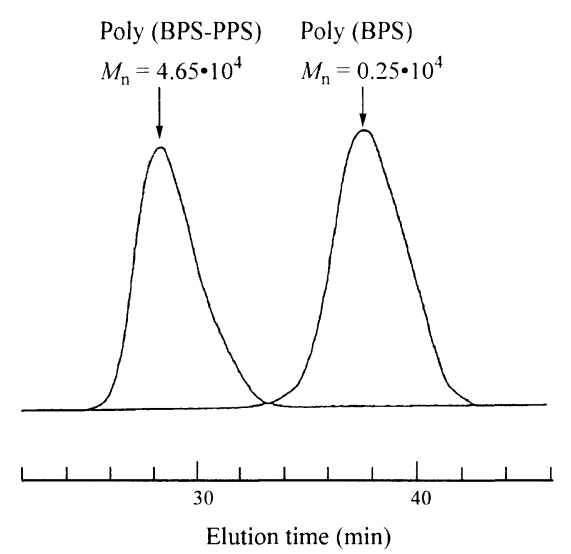

Figure 10. GPC profiles of poly(BPS) and poly(BPS-PPS) as in Figure 8.

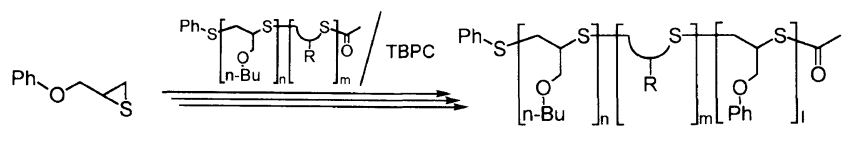

Scheme 4.

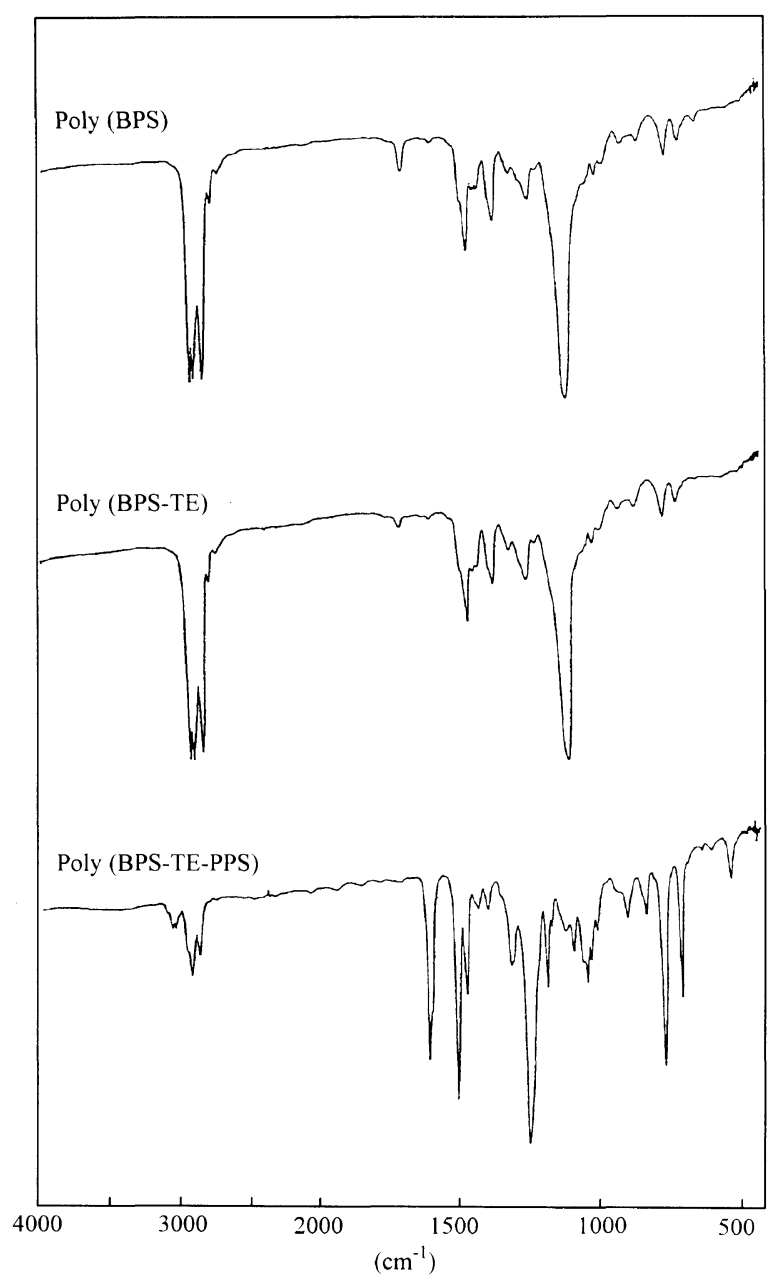

Figure 11. IR spectra of poly(BPS), poly(BPS-TE), and poly(BPSTE-PPS). Poly(BPS), $M_{n}=2500$; poly(BPS-TE), $M_{n}=2800$; poly (BPSTE-PPS), $M_{n}=33400$.
Figures 8 and 9 show the IR and ${ }^{1} \mathrm{H}$ NMR spectra of poly(BPS) and poly(BPS-PPS) block copolymer. In the IR spectrum of poly(BPS-PPS), the peaks based on the aromatic ring of PPS unit were observed at 1597 and $1499 \mathrm{~cm}^{-1}$, although the aromatic peaks were not observed in that of the prepolymer. Moreover, the intensity of peak due to the terminal $S-(\mathrm{C}=\mathrm{O})$ group decreased compared to that of poly(BPS). In the ${ }^{1} \mathrm{H}$ NMR of poly(BPS), acetyl protons and aromatic protons of each polymer terminal were observed at 2.33 and near 7.12-7.47 ppm, respectively. The ${ }^{1} \mathrm{H}$ NMR of poly(BPSPPS) shows the signals corresponding to the structure of the di-block copolymer. Furthermore, the weak signal due to the acetyl group at the terminal was observed at $2.34 \mathrm{ppm}$.

As shown in Figure 10, the unimodal GPC profile of poly(BPS-PPS) block copolymer was observed in the higher molecular region than that of poly(BPS). These spectral data and GPC profiles proved that the copolymerization of PPS with poly(BPS) in the presence of TBPC proceeded from the terminal $S$-acetyl group of the prepolymer in a group transfer reaction manner to give the targeted di-block copolymer.

Based on these results, synthesis of ABC-type of tri-block copolymers was performed by using di-block copolymers under the similar conditions (Scheme 4).

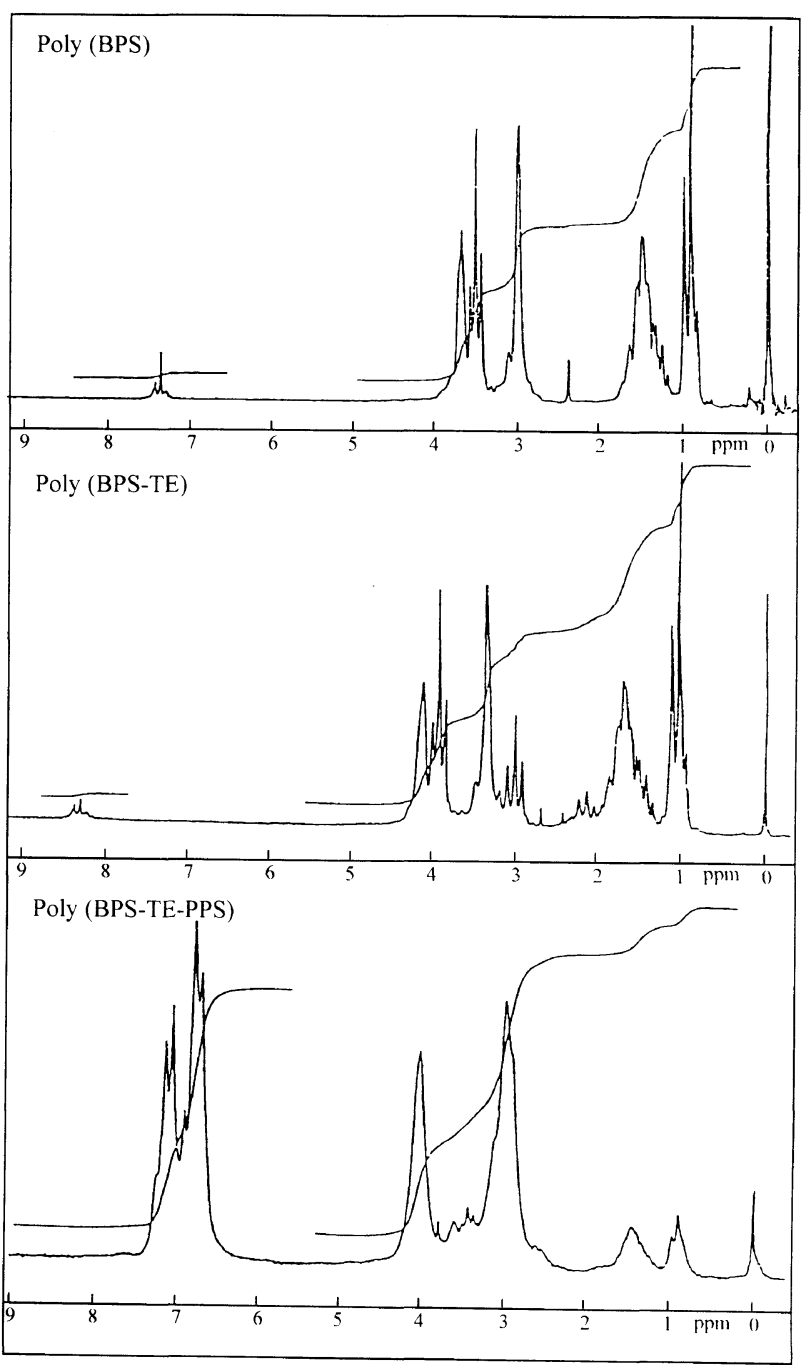

Figure 12. ${ }^{1} \mathrm{H}$ NMR spectra of poly(BPS), poly(BPS-TE), and poly(BPS-TE-PPS) as in Figure 11. 
Table V. Synthesis of di-block copolymers ${ }^{a}$

\begin{tabular}{|c|c|c|c|c|c|c|c|}
\hline \multirow{2}{*}{ Prepolymer } & \multirow{2}{*}{ Monomer } & Temp & Time & Yield $^{\mathrm{c}}$ & \multirow{2}{*}{ Composition $^{\mathrm{d}}$} & \multirow{2}{*}{$M_{n}^{\mathrm{e}}$} & \multirow{2}{*}{$M_{w} / M_{n}^{\mathrm{e}}$} \\
\hline & & ${ }^{\circ} \mathrm{C}$ & day & $\%$ & & & \\
\hline Poly(BPS) & CHS & 120 & 3 & 69 & $37: 63$ & - & - \\
\hline Poly(BPS) & $\mathrm{TE}^{\mathrm{b}}$ & 150 & 7 & 16 & $67: 33$ & 2800 & 1.13 \\
\hline
\end{tabular}

${ }^{\text {a }}$ The reaction was carried out with cyclic sulfides $(5 \mathrm{mmol})$ and poly $(\mathrm{BPS})\left(0.3 \mathrm{~g}, M_{n}=2500, M_{n} / M_{n}=1.03\right)$ using TBPC $(0.1 \mathrm{mmol})$ in anisole $(5 \mathrm{~mL})$ at $90{ }^{\circ} \mathrm{C}$. ${ }^{\mathrm{b}}$ Thietane. ${ }^{\mathrm{c}}$ Insoluble parts in methanol. ${ }^{\mathrm{d}}$ Determined by intensity ratios in ${ }^{1} \mathrm{H}$ NMR. ${ }^{\mathrm{e}}$ Estimated by GPC based on polystyrene standards.

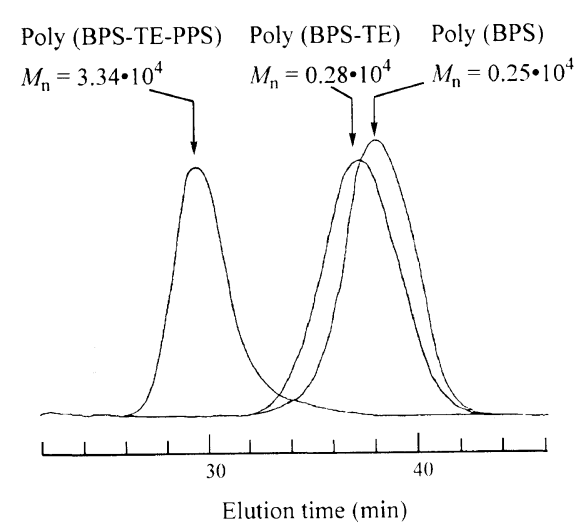

Figure 13. GPC profiles of poly(BPS), poly(BPS-TE), and poly(BPSTE-PPS) as in Figure 11.

When the polymerization of PPS with poly(BPS-CHS) previously prepared, was conducted using TBPC at $90^{\circ} \mathrm{C}$ for 3 days, the poly(BPS-CHS-PPS) with $M_{n}$ of 22100 was obtained in $94 \%$ yield. Tri-block copolymer, poly(BPS-TE-PPS) with $M_{n}$ of 33400 was also prepared in high yield by the reaction of PPS with poly(BPS-TE) under the same conditions. The change of IR spectra of poly(BPS), poly(BPS-TE), and poly(BPS-TE-PPS) suggested that the peak intensity of $\mathrm{C}=\mathrm{O}$ stretching of poly(BPS) terminal decreased gradually in that of di- or tri-block copolymer (Figure 11). The ${ }^{1} \mathrm{H}$ NMR spectra of those polymers supported their polymer structures (Figure 12). Moreover, the decrease of the intensity ratio of acetyl and aromatic protons of both terminal groups was also observed in the spectra of poly(BPS-TE) and poly(BPS-TE-PPS).

The change of GPC profiles of those three polymers was shown in Figure 13. It was found that the GPC profiles of poly(BPS-TE) and poly(BPS-TE-PPS) shifted maintaining the unimodal shape to the higher molecular regions than poly(BPS). These mean that the block copolymerization proceeded from the $S$-acetyl group at the di-block copolymer terminal without side reactions to afford the tri-block copolymers.

\section{CONCLUSION}

The present study demonstrated acyl-group transfer polymerization of thiiranes base on the regioselective addition reaction of thiiranes with carboxylic acids derivatives. The polymerization was achieved using active carboxylic acid derivatives such as acyl chlorides and $S$-thioesters as initiators and quaternary onium salts as catalysts. Di- and tri-block copolymers were successfully synthesized by the reaction of thiirane monomers with the various prepolymers using the same catalysts. It was proved that the polymerization of thiiranes proceeded transferring the acyl group at the growing polymer terminal to give the polymer with a stable $S$-acyl group as the end group. It was also revealed that the acyl-group transfer polymerization is of living nature.

Acknowledgment. This work was supported by a Grant-in-Aid for Scientific Research (No. 04855187) from the Ministry of Education, Science, and Culture of Japan, which is gratefully acknowledged.

\section{REFERENCES}

1. O. W. Webster, W. R. Hertler, D. Y. Sogar, W. B. Farnham, and T. V. RajanBaub, J. Am. Chem. Soc., 105, 5703 (1983).

2. As a review: A. H. Muller, Makromol. Chem. Symp., 32, 87 (1990).

3. For example; a) H. Catalgil, N. Vyanik, and C. Erbil, Polymer, 33, 655 (1992). b) K. G. Bannerjee and T. E. Hogen-Esch, Macromolecules, 26, 926 (1993).

4. R. P. Quirk and C. P. Bindinen, Polym. Bull., 22, 63 (1989).

5. R. P. Quirk and J. Rem, Macromolecules, 25, 6612 (1992).

6. D. Y. Sogah and O. W. Webster, Macromolecules, 19, 1775 (1986).

7. T. Hirabayashi, T. Itoh, and K. Yokota, Polym. J., 20, 1041 (1988).

8. H. Sumi, K. Haraguchi, Y. Inai, T. Hirabayashi, and K. Yokota, Polym. J., 26, 1262 (1994).

9. T. Nishikubo and A. Kameyama, Prog. Polym. Sci., 18, 963 (1993).

10. A. Kameyama, M. Kiyota, and T. Nishikubo, Tetrahedron Lett., 35, 4571 (1994).

11. A. Kameyama, S. Watanabe, E. Kobayashi, and T. Nishikubo, Macromolecules, 25, 2307 (1992).

12. A. Kameyama, Y. Yamamoto, and T. Nishikubo, J. Polym. Sci., Part A, Polym. Chem., 31, 1639 (1993).

13. A. Kameyama, K. Shimotsuma, and T. Nishikubo, Macromol. Rapid Commun., 15, 335 (1994).

14. R. Ketcham and V. P. Shah, J. Org. Chem., 28, 229 (1963). 